\title{
Antecedents and outcome of job embeddedness: Evidence from four and five-star hotels
}

\begin{abstract}
The present study explores the antecedents and outcome of job embeddedness. The antecedents are: level of control over work hours and felt obligation. The outcome is proactive customer service performance. Using self-administered questionnaires, 163 paired responses were gathered from frontline employees and their supervisors/managers in 16 hotels/resorts with a rating of four and five stars in Malaysia. Frontline employees responded to the questions on level of control over work hours, felt obligation and job embeddedness (on-the-job and off-the-job). Supervisors/managers responded to the questions on their employees' proactive customer service performance. The salient findings are: (1) Level of control over work hours and felt obligation have significant relationships with on-the-job embeddedness; (2) On-the-job embeddedness has a significant relationship with proactive customer service performance; (3) On-the-job embeddedness mediates the relationship between felt obligation and proactive customer service performance; and (4) Off-the-job embeddedness has a significant relationship with on-the-job embeddedness.
\end{abstract}

Keyword: Off-the-job embeddedness; On-the-job embeddedness; Proactive customer service performance; Level of control over work hours; Felt obligation; Hotel frontline employees 